\title{
Pengendalian RKPG dan Pendampingan Pemerintah Gampong Melalui Kemitraan BAPPEDA di Kecamatan Meurebo, Aceh Barat
}

\author{
Nellis Mardhiah' ${ }^{1}$ Ikhsan $^{2}$ Said Achmad Kabiru Rafiie ${ }^{3}$ \\ 1,2,3 Jurusan Ilmu Administrasi Negara, Universitas Teuku Umar \\ Email: nellismardhiah@utu.ac.id \\ Email: ikhsan.baharudin@utu.ac.id \\ Email: rafi@utu.ac.id
}

Submitted: 18 November 2019 Revised: 18 Desember 2019 Accepted: 22 Desember 2019

\begin{abstract}
The term Gampong means village which is a division of administrative territory in the province of Aceh, Indonesia. Thus, the Village Development Work Plan (RKPG) which is an obligation in the governance of the development of the Village of Gunong Kleng for the sake of community life. This RKPG becomes the obligation of the regional government in guiding the Gampong government apparatus in development management in accordance with applicable regulations. The general objective of this service is to build a good partnership between BAPPEDA and the Desa government in realizing the regional development strategic plan through a bottom-up approach in sustainable development plans. Procurement method is done with lectures and discussions to deepen public knowledge. The results of the socialization of assistance in community service activities to the Gampong community through 4 (four) stages are the FGD on RKPG and RPJMG provisions, the socialization of the MURENBANGDES Implementation Mechanism, the implementation of social control mechanisms which is directly imposed by the community in accordance with the provisions of the RKPG. After the socialization, RKPG hopes in the Gunong Kleng village to plan the development of the Gampong in accordance with the Gampong RPJMG that has been set up. The implementation of the development can increase community participation, and can increase the value of public trust in the Gampong government in transparent, accountable and sustainable development governance in Gampong Gunong Kleng Aceh Barat.
\end{abstract}

Keywords: Control, Accompaniment, Partnership

\begin{abstract}
Abstrak
Istilah Gampong sama artinya dengan Desa yang merupakan pembagian wilayah administratif di provinsi Aceh Indonesia. Sehingga, Rencana Kerja Pembangunan Gampong (RKPG) yang menjadi kewajiban dalam tata kelola pembangunan Gamponggunong Kleng demi kesejahtraan kehidupan masyarakat. RKPG ini menjadi kewajiban pemerintah daerah dalam pembinaan aparatur pemerintah Gampong dalam tata kelola pembangunan sesuai dengan peraturan yang berlaku. Tujuan umum pengabdian ini dilaksanakan untuk membangun kemitraan yang baik BAPPEDA dan pemerintah Gampong dalam menwujudkan rencana strategis pembangunan deerah melalui pendekatan bottom-up dalam rencana pembangunan yang berkelanjutan. Metode pengbadian dilakukan dengan ceramah dan diskusi untuk memperdalam pengetahuan masyarakat. Hasil sosialisasi pendampingan dalam kegiatan pengabdian kepada masyarakat Desa melalui 4 (empat) tahap adalah FGD tentang ketentuan RKPG dan RPJMG, Sosialisasi Mekanisme Pelaksanaan MURENBANGDES, Penerapan mekanisme sosial kontrol secara lagsung oleh masyarakat sesuai dengan ketetuan RKPG. Setelah sosialisasi harapannya RKPG di Gampong Gunong Kleng dapat menrencanakan pembangunan Gampong sesuai dengan RPJMG Gampong yang telah ditetapkan, Pelaksanaan pembangunan dapat meningkatkan partispasi masyarakat, serta dapat meningkatkan nilai kepercayaan masyarakat kepada pemrintah Gampong dalam tata kelola pembangunan secara transparan, akuntabel dan sustainable development di Gampong Gunong Kleng Aceh Barat.
\end{abstract}

Kata Kunci: Pengendalian, Pendampingan, Kemitraan 


\section{PENDAHULUAN}

Pemerintahan Desa merupakan lembaga pemerintah secara desentralisasi yang memiliki peran strategis dalam pengaturan pembangunan masyarakat menuju pembangunan nasional. Pemerintah Desa memiliki peranan yang sangat penting dalam pengelolaan proses sosial di dalam masyarakat. Tugas utama yang sangat berat yang harus dilaksanakan menciptakan kehidupan yang demkratik damai dan tentram dalam memberikan pelayanan sosial yang baik. Demikian pula Guna mewujudkan tugas tersebut, maka pemerintah Desa dituntut untuk melakukan perubahan secara terus menerus baik dari segi kepemimpinan maupun kinerja birokrasi yang berorientasi pada pelayanan Desa, sehingga benar-benar semakin mengarah pada praktik good governance, bukan bad governance (Wegrich, 2007)

Desa merupakan wilayah yang sangat strategis untuk membangun sebuah negara. Oleh karena itu, rencana kerja pemerintah Desa menjadi ujung tombak dalam mengidentifikasi kebutuhan masyarakat di level akar rumput sampai perencanaan dan realisasi tujuan bernegara hanya terdapat di tingkat level pemerintah Desa. Masalahnya adalah 60 per-sen penduduk Indonesia hidup di wilayah Desa dan fakta menunjukkan bahwa angka putus sekolah paling tinggi ada di level wilayah ini. Demikian pula masalah kesehatan, seperti balita dengan gizi buruk dan risiko kematian pada ibu melahirkan, terdapat paling polemik. Diperparah lagi dengan kondisi ketertinggalan perekonomian masyarakat Desa yang memicu meningkatnya jumlah angka kemiskinan Negara (Kessa, 2015).

Naskah Peraturan pemerintah dalam menwujudkan perencanaan pembangunan Desa menuju pembangunan Desa yang madiri berdasarkan Undang-Undang Nomor 6 Tahun 2014 Tentang Desa. Namun disisi yang lain dalam peraturan pemerintah ini tidak dijelaskan sera konkret tentang parameter Desa mandiri. Maka capaian dan tujuan sasaran pembangunan Gampong tidak dapat di rincikan dengan jelas oleh banyak orang maupun institusi menafsirkan makna Desa mandiri atau Desa Mandiri berdasarkan argumentasi masing-masing. Asumsi dari persoalan ini, penulis mencoba memberikan landasan konseptual teoritis mengenai kemandirian Desa yang dimaknai melalui perspektif pemberdayaan masyarakat melalui pendampingan secara kesinambungan sesuai dengan ketentuan dalam Rencana 
Kerja Pemerintah Gampong (RKPG).

RPJM Desa merupakan disusun untuk jangka waktu 6 (enam) tahun dan RKP Desa penjabaran dari RPJM Desa yang disusun untuk jangka waktu 1 (satu) tahun. Penysusunan RKP Desa, terdiri dari 9 (sembilan) tahapan sesuai dengan Peraturan Menteri Dalam Negeri Nomor 114 Tahun 2014 tentang Pedoman Pembangunan Desa yang meliputi ; (1) Penyusunan perencanaan pembangunan Desa melalui musyawarah Desa, (2) Pembentukan tim penyusun RKP Desa, (3) Pencermatan pagu indikatif Desa dan penyelarasan program/kegiatan masuk ke Desa, (4) Pencermatan ulang dokumen RPJM Desa, (5) Penyusunan rancangan RKP Desa, (6) Penyusunan RKP Desa melalui musyawarah perencanaan pembangunan Desa, (7) Penetapan RKP Desa, (8) Perubahan RKP Desa, dan (9) Pengajuan daftar usulan RKP Desa. Untuk menghindari tumpang tindih dalam pelaksanaannya, maka alur kegiatan harus berjalan sesuai dengan tahapan yang ditetapkan dan dalam kondisi normal tidak boleh ada tahapan yang dilompati(Suprastiyo, 2018).

Gampong Gunong Kleng salah satu Gampong yang terletak di Kecamatan Meurebo Kabupaten
Aceh Barat yang telah menjalankan kewajiban pemerintah secara partisipatif dalam perencanaan pembangunan. Indikasi ini salah kegiatan dan kewajiban pemerintah dalam menyongsong dana Desa yang harus diproritas dalam memenuhi undang-undang Nomor 6 Tahun 2014 tentang Desa .

Rencana Kerja Pemerintah Desa (RKPG) dilakukan setiap tahun menjadi salah satu hal yang cukup menarik, karena kegiatan ini menjadi agenda rutin yang dijalankan oleh pemerintah daerah pada tahapan pembangunan dengan penglibatan masyarakat. Penglibatan ini telah dilakukan dalam kegiatan MUSRENBANGDES dalam rangka penyusunan RKPG secara partispatif .

Pelibatan masyarakat dalam kegiatan RKPG yang selama ini dilaksanakan cenderung menjadi polemik dalam dinamika masyaakat Desa dan menjadi polemik dalam unsur masalah yang mendasar dalam proses perencanaan pembangunan Desa. Pemerintah daerah hanya memberi ruang bagi masyarakat untuk ikut berpartisipasi dalam proses perencanaan pembangunan. Namun dalam tahapan dan prosesnya penetapan program kegiatan akan ditetapkan sebagai sebuah kebijakan terkadang tidak 


mengakomodir usulan bagi
kebutuhan masyarakat. Ruang yang
diberikan pemerintah kepada
masyarakat hanya sekedar untuk
memenuhi kebutuhan regulasi
dalam undang-undang nomor 25
tahun 2004 yang mensyaratkan
bahwa mekaniske perencanaan
pembangunan
memprioritaskan tetap
masyarakat secara r meluas
(Harahap, 2012).

Demikian keadaan diatas menunjukkan di Gampong Gunong Kleng harus dikontrol dan dikendalikan melalui pendampingan dengan mitra dengan BAPPEDA Kabupaten Aceh Barat mulai dari dari pola penyusunan RKPG nya, mekanisme pengontrolan dalam pelaksanaan kegiatan demi keberlangsungan pembangunan yang berkelanjutan sesuai dengan visi dan misi Rencana Pembangunan Gampong yang telah ditetapkan.

\section{METODE PELAKSANAAN}

Pengabdian ini menggunakan pendekatan metode pelatihan dengan sumber utama proses dan informasi tentang pengabdian terhadap badan publik dalam pelatihan kepada aparatur Desa di Kecamatan Meurebo Kabupaten Barat. Secara umum, konsep pemantauan perencanaan pembangunan yang dijadikan sebagai landasan untuk Membangun rancangan pembangunan Desa. Maka dalam kegiatan ini yang menjadi mitra dalam kegiatan yang telah berlangsung adalah, peme pemerintah daerah, BAPPEDA, perguruan tinggi, serta organisasi masyarakat sipil dan keterwakilan aparatur Desa di wilayah Aceh Barat. Metode yang digunakan dalam pelaksanaan pengabdian adalah adalah: dilakukan dengan sosialisasi dan diskusi sosialisasi pengendalian RKPG dan pendampingan pemerintah Desa dengan mitra bappeda kecamatan meurebo, aceh barat.

\section{HASIL DAN PEMBAHASAN}

Pembinaan dan pendampingan Desa menjadi tema penting yang perlu dibicarakan Tujuan awal pendampingan adalah, untuk membantu dan mempersiapkan Desa di berbagai aspek, terutama menyangkut kapasitas menghadapi perubahan fundamental sebagaimana diisyaratkan pada misi besar transformasi Desa. Sementara, pengawasan dimaksudkan agar, sistem demokrasi dan praktik akuntabilitas penyelenggaraan pemerintahan dan pembangunan Desa dapat berjalan dengan baik. Itulah tujuan mulia yang penting dimengerti. Masalahnya adalah, masing-masing Desa di Indonesia 
yang jumlahnya kurang lebih 74.910 itu, belum memiliki persiapan yang sama di berbagai aspek.

Kita menyadari bahwa kapasitas kelembagaan dan SDM perangkat maupun masyarakat untuk penyelenggaraan pemerintahan dan pembangunan, serta pengawasannya dalam kenyataannya masih lemah dan terbatas. Tentu hal ini tidak bisa ditimpakan sebagai kesalahan , karena sesungguhnya hanya menjadi korban kebijakan masa lalu yang dapat dikatakan salah urus. Sejarah menjadi catatan penting mengapa situasi seperti itu terjadi. Bagaimanapun juga kondisi dan nasib di Indonesia memang cukup beragam. Sebelum regulasi baru itu lahir, rata-rata nasib mereka termarginalkan.

Beban struktural yang dialaminya, sebagai warisan kebijakan lama terutama dijaman orde baru yang wataknya otoriter saat itu telah merusak eksistensi . Jika bicara, diidentikkan dengan situasi kemiskinan, keterbelakangan dan ketertinggalan. Itulah fakta sejarah. Perlakuan negara pada secara salah pada saat itu, mengakibatkan ketergantungan pada negara. Pola rekayasa dan dominasi supra telah menghancurkan sendi-sendi otonomi . Dengan berbagai cara dilumatkan secara paksa melalui politik homogenisasi, yang pada saat itu pemberlakuan regulasi represif UU No. 5 tahun 1979 tentang Pemerintahan Desa.

Proyek penguasaan negara pada mengakibatkan pelumpuhan sistematik oleh aktor-aktor negara yang beramai-ramai menguasai sumberdaya bersekutu dengan pemilik modal mengeksploitasinya atas nama pembangunan. Disitulah bentuk perampasan otonomi oleh negara, karena pembangunan dirancang dari atas dan sesuai selera pemilik modal. Suatu cerita kelam masa lalu. Sekalipun ada sejumlah yang kebetulan bernasib baik, hal itu rata-rata karena daerahnya kaya, atau dapat dikatakan kebetulan pemimpin daerahnya berhati baik.

Pemberdayaan Masyarakat adalah upaya mengembangkan kemandirian dan kesejahteraan masyarakat dengan meningkatkan pengetahuan, sikap, keterampilan, perilaku, kemampuan, kesadaran, serta memanfaatkan sumber daya melalui penetapan kebijakan, program, kegiatan, dan pendampingan yang sesuai dengan esensi masalah dan prioritas kebutuhan masyarakat (Karimah, Faizatul; Saleh, Kahirul ; Wanusmawatie, 2017).

Perencanaan pembangunan atau adalah proses tahapan kegiatan yang diselenggarakan oleh 
pemerintah dengan melibatkan Badan Permusyawaratan (BPD) dan unsur masyarakat secara partisipatif guna pemanfaatan dan pengalokasian sumber daya dalam rangka mencapai tujuan pembangunan . Tujuan pembangunan yaitu mengenai bidang perencanaan pembangunan , pelaksanaan kegiatan pembangunan, serta pemantauan dan pengawasan pembangunan (Sugiharto, 2019).

Metode pelaksanaan perencanaan pembangunan secara efektif dapat dikendalikan melalui dua tahapan proses kegiatan dalam rencana pembangunan yang efektif dan efisien yakni sebagai berikut:

\section{Sosialisasi Program Rencana Pembangunan}

Pendekatan sosialisasi RKPG dapat dilakukan melalui pendekatan rancangan pembangunan melalui dua model rencana pembangunan yakni, pertama; Top-down Playning, yakni BAPPEDA di Kabupaten Aceh Barat memiliki kewenangan untuk mengontrol pembangunan sesuai dengan tujuan dan sasaran yang telah ditetapkan dalam visi dan misi pemerintah daerah. Penetapan visi dan misi ini dapat dikontrol melalui RKPG yang diusulkan agar dapat disesuaikan dengan ketentuan yang berlaku. Proses penyusunan RKPG tahunan senanatiasa menjadi kewajiban pemerintah yang harus disesuaikan dengan mekanisme policy brief yang secara kesinambungan agar perencanaan pembangunan dan pelaksanaan tepat sasaran. Tahapan yang kedua; Bottom-up Playning, langkah ini menjadi kunci utama dalam RKPG yang efektif efisien dalam kegiatan MUSRENBANGDES dengan melibatkan seluruh elemen dasar modal sosial masyarakat dalam merencanakan pembangunan.

Elemen dasar yang dimaksud masyarakat ikut secara partisipati secara aktif dalam pengedalian sosial RKPG agar sesuai dengan tujuan dan sasaran kegiatan perencanaan pembangunan .

Berikut disajikan pada Gambar 1 dan 2 kegiatan sosialisasi program RKPG melalui kemitraan dengan BAPPEDA Kabupaten Aceh Barat.

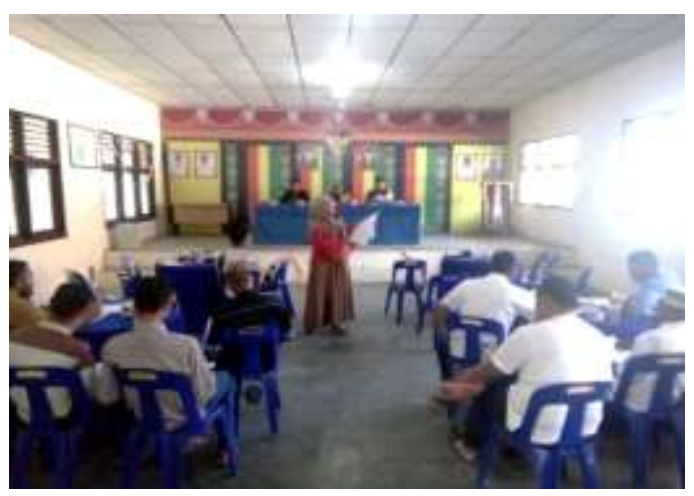

Gambar 1. Pematari Sedang Mempresentasi Materi Tentang Pengendalian RKPG 


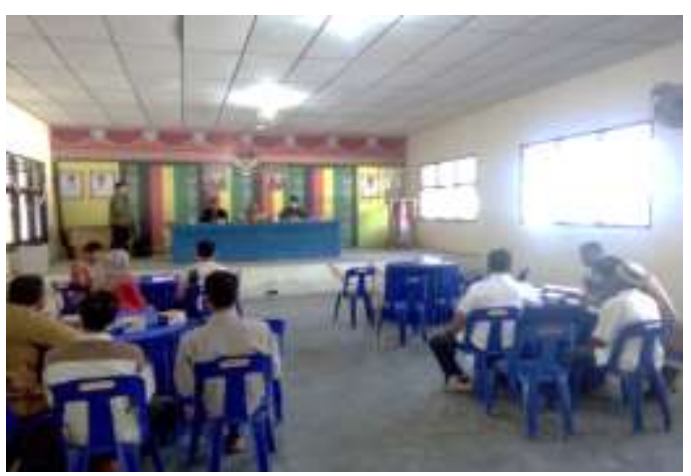

Gambar 2. Sesi Tanya Jawab

Dengan Perserta Serta Sosialisasi

\section{Pengendalian Program RKPG}

Langkah pengendalian program merupakan elemen modal sosial adalah masyarakat yang ikut serta secara langsung dapat mengontrol pelaksanaan pembangunan sesuai dengan RKPG yang telah disepakati bersama melalui kegiatan MUSRENBANGDES. Adapun yang menjadi elemen modal sosial dalam dalam pembangunan secara partisipatif dapat disajikan sebagai berikut:

a. Data Rencana Program Dan Kegiatan Perencanaan Pembangunan;

b. Pendataan potensi dan masalah di;

c. Dokumen Rekapitulasi Gagasan Dusun;

d. Laporan hasil pengkajian keadaan;

e. Musyawarah penyusunan RPJG;

f. Rancangan RPJG;

g. Musyawarah perencanaan pembangunan; h. Musyawarah penyusunan RKPG;

i. Dokumen pagu indikatif;

j. Rancangan RKPG;

k. Proposal Teknis dan kelengkapannya;

1. Verifikasi dan pemeriksaan proposal teknis;

m. Daftar usulan RKPG;

n. Berita acara tentang hasil penyusunan rancangan RKPG;

o. Berita acara Rancangan RKPG melalui musyawarah perencanaan pembangunan.

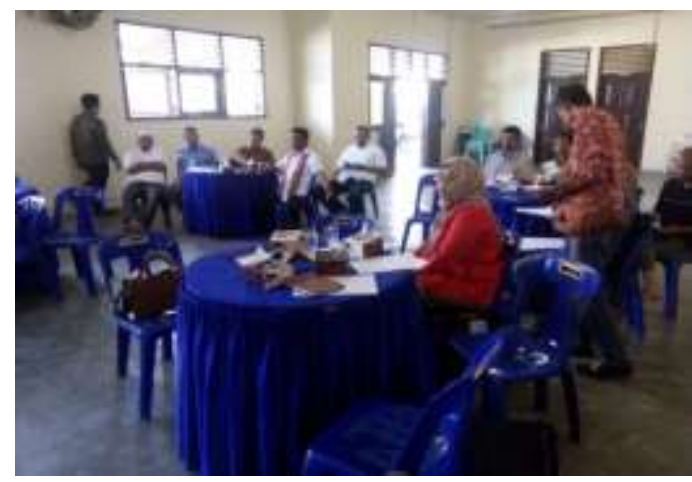

Gambar 3. Diskusi dan

Pendalaman Materi

Tujuan pelaksanaan kegiatan ini dilaksanakan untuk kegiatan Pemberdayaan Masyarakat adalah sebagai upaya mengembangkan kemandirian dan kesejahteraan masyarakat dalam peningkatan sumberdaya manusia secara sofkil maupun hardkil dalam penyusunan program, kegiatan, dan pendampingan yang sesuai dengan masalah dan skala prioritas kebutuhan masyarakat sesuai dengan visi dan misi pemerintah 
Dearah yang telah ditetapkan Gambar 4 form kontrol melalui perencanaan BAPPEDA dalam pembangunan secara pengendalian dalam kegiatan berkelanjutan. Berikut disajikan perencanaan pembangunan desa.

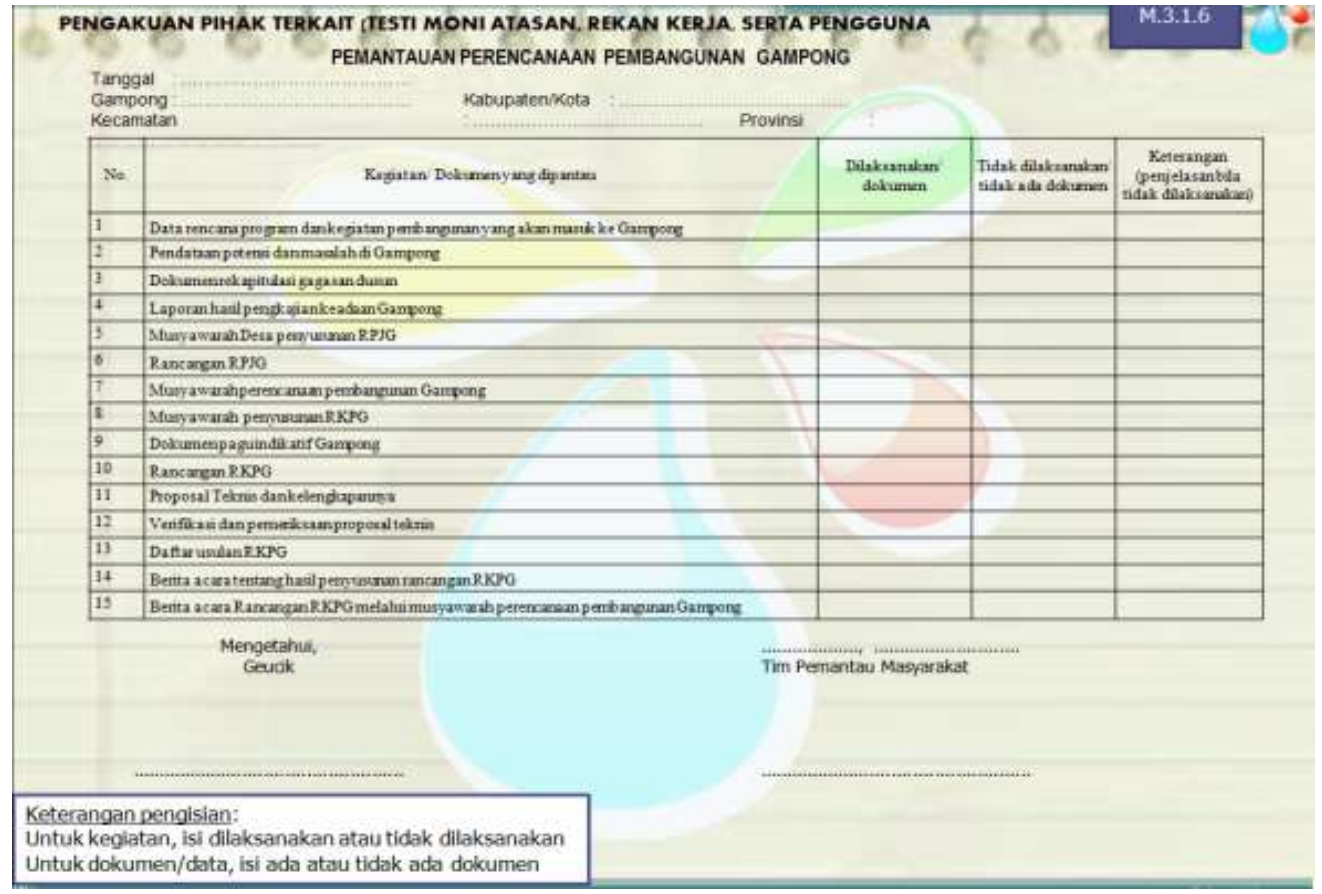

Gambar 4. Form Pengendalian dalam Perencanaan Pembangunan Desa

\section{PENUTUP}

Model Pendampingan yang telah dilakukan melalui sosialisasi program RKPG sesuai dengan tujuan dan sasaran pembangunan yang berkelanjutan. Kemitraan BAPPEDA yang dibentuk dalam rancangan kegiatan pembangunan yang berkelanjutan. Maka untuk itu, model pembangunan ini dalam Penyusunan RKPG didampingi harus adanya pengendalian dan pengontrolon modal sosial dengan keterlibatan masyarakat sebagai aktor utama dalam perencanaan dan pelaksanaan dan evaluasi agar program perencanaan program sesuai dengan harapan masyarakat.

5. DAFTAR PUSTAKA

Harahap, E. F. (2012). Pemberdayaan Masyaarakat dalam Bidang Ekonomi untuk Mewujudkan Ekonomi Nasional Yang Tangguh dan Mandiri. Jurnal Manajemen Dan Kewirausahaan, 3(2), 78-96.

Karimah, Faizatul ; Saleh, Kahirul ; Wanusmawatie, I. (2017). Pengelolaan Alokasi Dana Desa dalam Pemberdayaan Masyarakat. Jurnal Administrasi Publik (JAP), 2(4), 597-602. 
Kessa, W. (2015). Perencanaan

Pembangunan Desa. Jakarta:

Kementerian Desa,

Pembangunan Daerah

Tertinggal dan Transmigrasi.

Sugiharto, S. (2019). Teknik

Penyusunan Rencana Kerja

Pemerintah Desa (RKP Desa)

USAID. Jakarta: Pusat Penelitian

dan Pengembangan Kementrian

Desa dan Pengembangan

Kementrian Desa Pembangunan

Daerah Tertinggal dan

Transmigrasi.

Suprastiyo, A. M. (2018).

Implementasi Penyusunan

Rencana Kerja Pemerintah (RKP) Desa (Studi di Desa Trucuk Kabupaten Bojo Negoro). Jurnal JIMPKS, 2(2), 255-265.

Wegrich, K. (2007). Revolusian In Bevir Mark (Ed), Ecylopodia Of Governance. California: SAGE Publication, Inc. 